\title{
Uma história ensinada para Homer Simpson: negacionismos e os usos abusivos do passado em tempos de pós-verdade
}

\author{
A History Taught to Homer Simpson: Denialism \\ and Abusive Use of the Past in Times of Post-Truth
}

Sônia Meneses*

\section{Resumo}

$\mathrm{O}$ artigo problematiza a emergência de histórias públicas reacionárias e novos negacionismos influenciados pela profusão de narrativas históricas vinculadas aos meios de comunicação e às ideias de pós-verdade. Assim, destacam-se as relações entre história, mídia e ensino, abusos do passado, difusão de narrativas históricas e consumo. Ao final, aponta para os desafios colocados ao próprio lugar da história e dos professores de história frente a essa produção. Palavras-chave: História Pública; pós-verdade; negacionismo; ensino.

\begin{abstract}
This article approaches the emergence of digital discourse and the new Negationism influenced by the historical narratives linked to the media; draft the relations between history, the media and education, the abuses of the past, the diffusion of historical narratives and consumption. In the end, it points to the challenges to the very place of the history and the teachers of history in front of to the concept of post-truth.

Keywords: Public History; post-truth; negationism; teaching.
\end{abstract}

No dia 2 de fevereiro deste ano [2017], uma equipe do History Channel veio a minha casa. Entrevistou-me para o que seria, segundo me informaram, genericamente, "uma série sobre a história do Brasil": Tomaram quase duas horas de meu tempo. Fiquei pasmo quando o entrevistador, Matheus Ruas, da produtora Fly, pediu-me explicitamente para responder às questões como se, do outro lado da lente, sentado na poltrona, estivesse o Homer Simpson. (Lira Neto, 20 out. 2017)

Façamos um exercício: pensemos em Homer Simpson, como um tipo ideal, querendo aprender história do Brasil. Personagem de instrução

\footnotetext{
* Universidade Regional do Cariri (Urca), Crato, CE, Brasil. sonia.meneses@gmail.com
} 
elementar que, embora tenha frequentado a escola, não avançou muito nos processos de compreensão do mundo a sua volta. Homer é totalmente desconectado das questões sociais, políticas ou mesmo ambientais em seu entorno. Frequentador do mesmo bar com seus amigos homens, por décadas, instruiu-se, basicamente, pela televisão, centro de suas apropriações culturais. O personagem tem caráter duvidoso, porque quase sempre só consegue perceber suas necessidades em detrimento de qualquer outra pessoa, até mesmo, de seus filhos; nesse sentido, raramente muda sua conduta e, mesmo quando enfrenta as maiores atribulações, não tem grandes problemas existenciais ou de consciência; continua o mesmo.

Há também pouca ou nenhuma preocupação ética ou de responsabilidade ligada ao personagem. Homer apenas vive seu cotidiano, não pensa nem reflete sobre ele, embora seus filhos tragam características diferentes, a exemplo de Lisa, a filha mais velha, que representa seu oposto.

Criado em 1985 pelo cartunista Matt Groening, ${ }^{1}$ o icônico personagem é uma sofisticada caricatura. Embora diga muito da própria cultura norte-americana, é a representação de alguns elementos gerais que podemos identificar em nossa sociedade contemporânea. Homer é um pai de família, classe média baixa, cuja gramática de percepção do mundo se limita ao seu restrito cotidiano. Também parece não gostar muito de história. Num episódio emblemático do programa, em que Marge, sua esposa, relembra seu tempo de faculdade, quando cursava uma disciplina de história da arte, assistimos ao seguinte diálogo:

Marge: Homer, os meus horizontes se abriram: sabia que todos os presidentes dos EUA foram homens brancos e heterossexuais?

Homer: Até o Walt Disney?

Marge: E também, sabia que a história é escrita pelos vencedores?

Homer: É mesmo? Achei que fosse escrita por perdedores! [Homer gargalha] ${ }^{2}$

Evidentemente, para Homer, os perdedores somos nós, historiadores e professores de história. No chiste, percebe-se o desprezo de Homer pela informação trazida por Marge. Quem se interessa em saber disso? É a questão implícita na gargalhada de Homer.

Sua caracterização, seus gestos, sua maneira de ver o mundo de alguma forma agregam as representações de uma sociedade consumidora, capitalista 
e ordinária. Mas o que significa pensar uma história a ser ensinada para Homer, a qual o jornalista Lira Neto, como vimos, mostrou-se chocado em ter de realizar? Buscando formular algumas respostas a essas questões, eu gostaria de começar enfrentando aqui, em primeiro lugar, as ideias de apropriação, consumo e controle a partir do conceito de "ordinário". Além disso, procurarei compreender as intenções de uma educação histórica para grandes audiências que tem a vulgarização de conteúdos como meta.

\section{UMA HISTÓRIA ORDINÁRIA?}

Ordinário, conforme nos informa o Houaiss, é aquilo que está em conformidade com a ordem, o habitual, do latim, ordinarius, disposto em ordem. Aquilo que se reproduz seguidamente. Em outro sentido, o termo adquire o significado daquilo cujo valor intelectual é considerado fraco, menor, reles. Ao nos referirmos a alguém, pode representar ainda o sujeito de má índole, sem caráter, vulgar. Aqui, gostaria de abordar o conceito com base nas produções de história presentes em nosso cotidiano, especialmente aquelas que ganharam as ruas, os espaços televisivos, as redes sociais. Nesse sentido, advirto que ordinário, aqui, pode congregar a dupla significação que o termo encerra.

Ao longo dos anos, diversos trabalhos historiográficos têm se questionado sobre o cotidiano, as experiências dos homens comuns na história, as micro-histórias de sujeitos e eventos que serviram para ressaltar a complexidade da cultura, do imaginário, do simbólico. Muitas dessas obras surgiram em resposta a questões como: Ao falarmos de ordinário, falamos do popular? Nos referimos a aspectos de uma cultura específica? Ao senso comum ou, ao excepcional?

Em sua obra já clássica, A invenção do cotidiano (1998), Certeau nos desafiou a pensar as práticas de uma cultura ordinária. Para ele, o ordinário descortinava um rico caleidoscópio de cores do cotidiano. Assim nos propôs que mergulhássemos em um conjunto de práticas e ações que evocavam "artes de fazer”, invenções, solidariedades, lutas dissimuladas; um conjunto de arranjos, de resistências e táticas que se infiltram entre as duras engrenagens que fazem o controle e o poder se movimentarem.

Em Certeau, portanto, compreender uma cultura ordinária é pensar as criatividades, as invencionices, as bricolagens que transformam a sociedade 
continuamente por meio de silêncios, nas ações de excluídos, em rotinas e frestas que nos demonstram uma vibrante rede de antidisciplina que age sub-repticiamente modificando estruturas disciplinares estabelecidas.

Podemos dizer, dessa forma, que no ordinário certeuaniano encontramos uma potência da transformação; uma dimensão latente de resistência que ajuda a burlar a norma e o controle. Além disso, o instrumental oferecido pelo autor nos apresenta um panorama exemplar para compreendermos como as relações de força funcionam em nossas sociedades, tendo por base um modelo dinâmico estratégico-tático.

Ao identificar o lugar do "próprio", compreendido como o lugar disciplinar no qual se produzem discursos e formas de controle, o autor o qualifica como o lugar de uma produção expansionista, barulhenta e espetacular. A ela sobrevém outra, qualificada por ele de consumo, que é dispersa, silenciosa e quase invisível, mas também, criativa. O espaço da apropriação. Estabelece-se aí uma espécie de circuito que movimenta um conjunto de práticas que se opõem e se alimentam continuamente.

O autor chama essa movimentação de "consumo", o qual podemos entender como a maneira pela qual as pessoas conseguem operar, lidar com aquilo que lhes é imposto, comunicado, ou simplesmente apresentado como produto cultural. Mas é preciso considerar que do próprio consumo resulta outra produção: "produção por apropriação", permitam-me chamar assim.

Para nós, pesquisadores e professores, entender o consumo é olhar por fissuras que podem nos informar tanto sobre o controle, como sobre as criatividades da resistência a ele. Mas aqui eu gostaria de apontar uma complicação. Gostaria de sugerir considerarmos os meandros dessa história ordinária, produzida através da grande mídia para amplas audiências, a partir desta configuração: as disputas entre dois lugares de "próprio", conforme definia Certeau. É próprio, ou seja, disciplinar, o lugar da história, convencionalmente articulada com base na produção historiográfica tradicional. É a ele que, nos dois últimos séculos, se atribuiu o espaço de legitimação de conteúdos históricos que orienta, normatiza, propõe as mudanças de abordagens e estabelece protocolos para essa produção. Mas no tempo presente deparamos com um fenômeno interessante: a insurgência de outros sujeitos a disputarem o controle desse lugar disciplinar - podemos chamar isso de outros "próprios". 
Refiro-me aos usos e tratamentos do passado para atingir amplas audiências, como na produção midiática de história.

Nesse sentido, essa última produção tem uma dupla característica que é, ao mesmo tempo, consumo e produção. Consumidora e produtora de história, que instrui sobre o passado, no caso de nossa história feita para Homer. Falarei de um tipo de consumo que aqui irei qualificar de apropriação conservadora sobre o passado, por conseguinte, produção conservadora de história.

Nesse caso, não uma apropriação que subverte uma dada ordem, mas, ao contrário, aquela que se serve de cânones tradicionais, de maneira simplificada, para criar outras formas de controle e perpetuação de poderes. Consumo reacionário que, no caso da história, pode também ser qualificado de abuso. Assim, de fato, podemos nos referir a uma história para Homer Simpson, na medida em que é uma história feita e pensada para conformar o sujeito, que não tem a preocupação em demovê-lo de seu estado letárgico de compreensão de mundo.

A produção de uma história mantenedora do status quo. Se nada demove Homer, a história a ser ensinada deve apenas entretê-lo, ser divertida, fazê-lo rir. Uma apropriação reativa que se vale de uma linguagem atualizada, criativa, mas que tem como objetivo desequilibrar procedimentos de reflexão sobre os processos históricos, desqualificar o papel do professor e de pesquisas históricas que não atendam as demandas políticas e os interesses desses novos produtores.

Assim, estabelece-se um claro conflito entre autoridade e competência, saber acadêmico e opinião. Uma produção que é, ao mesmo tempo, narrativa histórica e produto midiático. $\mathrm{O}$ conceito de consumo assim se alarga e torna-se também um problema de cidadania para nossas sociedades. O desafio é entender as narrativas históricas autodenominadas de "politicamente incorretas" como produtos efetivados não apenas no Brasil, mas fenômeno conservador observado em outros países, nas assim chamadas histórias revisionistas e, em alguns casos, claramente negacionistas. Nesse sentido volto agora ao episódio que envolveu o jornalista Lira Neto e outros pesquisadores e historiadores, por ocasião da gravação do programa de televisão voltado à história do Brasil. 


\section{ENSINANDO A SER NEGACIONISTA}

A Esquerda brasileira, que se diz ter combatido pela liberdade, mente! Grande parte dos professores de história também mente! (Luiz Felipe Pondé) ${ }^{3}$

Em 20 de outubro de 2017, Lira Neto relatou, em sua página do Facebook, que havia sido procurado para uma entrevista por um dos produtores do canal televisivo History ${ }^{4}$ que, naquele momento, produzia uma série sobre a história do Brasil. O jornalista esclareceu que, como faz sempre, aceitou o pedido, mas estranhou a forma como o produtor solicitou que ele respondesse às questões "como se, do outro lado da lente, sentado na poltrona, estivesse o Homer Simpson". Segundo ele, seu espanto foi maior quando, mais de um ano depois, com o programa prestes a ir ao ar, soube que na verdade se tratava de uma adaptação do livro Guia politicamente incorreto de História do Brasil, do também jornalista Leandro Narloch, informação que não havia tido na época. Lira Neto termina seu texto argumentando que:

Sinto-me violentado em fazer parte de qualquer produção que recorra à superficialidade e ao polemismo fácil. Neste momento em que se confunde jornalismo com entretenimento, bravata com reflexão, inconsistência com leveza, creio que seja necessário reafirmar o compromisso com a responsabilidade e o rigor da pesquisa histórica. (Lira Neto) ${ }^{5}$

Ironicamente, a reivindicação da responsabilidade e do rigor histórico não partem de um historiador convencional, mas de um jornalista que escreve história. Lira Neto é autor de biografias premiadas como as de José de Alencar e Getúlio Vargas. Escreveu ainda sobre Maísa e Padre Cícero e outros temas históricos. $\mathrm{O}$ autor se tornou um grande fenômeno de venda nos territórios dos historiadores, sendo suas obras adaptadas para a televisão, a exemplo da minissérie Maísa: quando fala ao Coração, inspirada em sua biografia e produzida pela Rede Globo em 2009.

Em comum, tanto Narloch como Lira Neto se inscrevem numa produção histórica que hoje podemos qualificar de pública. Embora esse campo de discussão seja mais amplo do que os produtos advindos dos meios de comunicação ou da produção jornalística, inegavelmente é a partir das várias mídias que temos a linha mais expressiva de conteúdos públicos voltados à história. No 
caso específico, refiro-me às narrativas que, nos últimos anos, avançaram velozmente na reflexão e tradução do passado e que podem ser produzidas tanto por historiadores como por profissionais de outras áreas com o objetivo de atingir um grande público.

A título de exemplo, notamos como o passado tornou-se uma febre na produção midiática, quando somente entre o ano de 2017 e o primeiro semestre de 2018, entre novelas e minisséries produzidas em canais abertos no Brasil, contabilizamos 11 programas ambientados em outras temporalidades, desde o século XVI a.C., passando pela Idade Média, até a década de $1980 .{ }^{6}$ Além da TV aberta, existem outros canais especializados em narrativas que pretendem se apresentar como lugares de educação histórica e especialistas em temas históricos como as produções dos canais History, H2, Discovery Civilization e uma série de outros produtos voltados ao tema. Embora esses canais façam parte do circuito fechado, são redistribuídos em vídeos do YouTube que ampliam muito sua audiência.

Num cenário tão diverso, algumas obras assumiram vieses claramente conservadores ou negacionistas, dissimuladas em linguagens atualizadas e formas de interação nas quais as maneiras de dizer importam mais do que o que é dito. $\mathrm{O}$ aparente frescor das imagens vibrantes, a participação de youtubers famosos na apresentação de conteúdos que seriam fruto de "pesquisas históricas sérias" ou a "descoberta" de novidades sobre o passado em grande medida se configuram numa releitura de antigos paradigmas que sustentam a manutenção de processos excludentes, preconceitos e conclusões que utilizam de forma desonesta as informações extraídas de teses e dissertações, ou mesmo fontes históricas, selecionadas e recortadas para referendar argumentos cujo fim é a desqualificação política de vários sujeitos e enunciados científicos.

Algumas delas inspiram estratégias discursivas quase milenaristas na medida em que estimulam uma cruzada assentada em polarizações do que seriam verdades e mentiras, "partidos" e "sem partidos", o bem contra o mal. Por isso é uma história que se anuncia como uma escolha entre contrários, numa dicotomia sectária que aniquila a complexidade do pensamento e a diversidade de ideias. Não por acaso, exalta-se o politicamente incorreto contra o politicamente correto, a escola sem partido contra a escola doutrinadora, ou a história verdadeira contra a história de esquerda. 
Ressalto que o problema não é o de jornalistas, advogados, memorialistas ou qualquer outro sujeito ou instituição escreverem sobre o passado, mas de compreendermos como esse passado é elaborado e, sobretudo, interrogarmos sobre seus efeitos nos processos de representação histórica em nossa sociedade. Se os historiadores precisam de seus pares para responder sobre suas obras, o que claramente coloca em evidência as responsabilidades da pesquisa histórica, quais os balizadores sociais e intelectuais de uma historiografia midiática desse tipo? Chamo de historiografia midiática toda a produção de leitura do passado que se ampara no universo dos meios de comunicação, em seus vários formatos, e que se destinam a grandes audiências.

Certeau (1998) demonstrou que, ao escrevermos história, deparamos com um complexo jogo de adequações, pressões e sistematizações que torna nossa produção circunscrita a um campo que construímos para dar legitimidade ao nosso conhecimento. Nesses termos, a produção historiográfica também está submetida às apropriações e pressões diversas, e, nas últimas décadas, esse lugar foi profundamente transformado pelas demandas sociais e políticas tanto internas quanto externas ao campo. Nesse processo, ressalto um elemento importante destacado por Certeau: na medida em que foi se desenvolvendo uma crescente especialização do saber, houve a emergência do perito, o sujeito que domina uma dada linguagem técnica e, portanto, está autorizado a falar em nome dela.

Progressivamente, esse sujeito do discurso científico tornou-se responsável por ser o intérprete e o tradutor de sua competência para outros campos em um processo no qual, muitas vezes, a autoridade da fala foi se sobrepondo à própria competência do saber, embora a primeira continuasse a se articular com a segunda. Se tal aspecto era percebido como um problema pelo eminente historiador, o desafio agora parece ser ainda mais complexo, na medida em que tanto a autoridade do historiador como a competência do saber histórico produzido nas últimas décadas têm sido seguidamente questionadas a partir de parâmetros totalmente externos a essa produção, como se houvesse uma história verdadeira a ser contada, em oposição àquela produzida pela historiografia dos historiadores.

Tais elementos podem ser considerados dentro de um processo de emergência reacionária que fala da "verdade" justamente para construir seu falso contrário. Nesse caso, para a popularização de certa escrita midiática de 
história foi necessário apostar na desqualificação dos discursos historiográficos acusados de partidários ou engajados.

Uma relação corrosiva que mistura as reflexões do saber histórico com o conjunto de preconceitos e interesses políticos que se apresentam como se fossem a verdade desse passado, na qual os produtores dessa historiografia midiática se colocam como intérpretes e tradutores de competência assentada na produção historiográfica e projetada para o grande público. Se em Certeau somos advertidos dos riscos de um saber que se constrói mais pela autoridade da fala do que pela competência de seus enunciados, o que dizer das constantes flutuações de autoridade sobre a produção de conteúdos históricos nas mídias? Sobre esse aspecto, o autor, ao tratar da história, também nos aponta caminhos para pensarmos a problemática recente:

No limite, quanto maior a autoridade do perito, menor sua competência, até o ponto em que seu fundo se esgota [...] Durante o tempo dessa conversão, não fica sem competência (tem que ter uma, ou ao menos fazer crer que tem) mas abandona a que possui na medida em que sua autoridade se estende para mais longe, exorbitada pela demanda social e/ou por responsabilidades políticas. Paradoxo (geral?) da autoridade: ganha o reconhecimento precisamente por um saber que lhe falta no terreno onde se exerce. (Certeau, 1998, p. 67)

Esse discurso, ainda segundo o autor, coloca em primeiro plano "questões estranhas à sua competência técnica, mas não ao poder que por ela se adquire", e desse modo pode "proferir autoritativamente um discurso que não é o do saber, mas o da ordem socioeconômica" (Certeau, 1998, p. 67). Situação bastante clara como vemos nas articulações dessas produções com os grandes grupos políticos e econômicos que distribuem esses conteúdos. Aqui, deparamos com as implicações entre argumento científico historiográfico e opinião, como destaca Dunker (2017, p. 40): “temos uma inversão sem contradição e, portanto, uma subjetividade que pensa com dificuldade sua própria temporalidade [...] ou sendo seu próprio processo de transmissão educativa percebido como manipulação e apossamento". Uma bricolagem mal-intencionada da competência historiadora, ao mesmo tempo que dela se serve para construir as informações que divulga como um valor de verdade para quem assiste, lê e escuta essa produção. 
É fundamental questionarmos ainda elementos que são muito próprios aos historiadores e regulados por nosso campo, mas que nos trabalhos dessas obras têm sido negligenciados, quais sejam: a ética na pesquisa histórica, as manipulações de dados e informações a fim de favorecer determinadas percepções da história e as falsificações de acontecimentos e registros em nome de demandas políticas e sociais. Elementos que são diferentes de pensarmos, por exemplo, as interpretações de conteúdos históricos, as revisões importantes de temas e objetos.

Constata-se que a produção historiográfica avançou significativamente sobre a compreensão de temas que assumiram lugar de destaque nas últimas décadas, tais como: as relações de gênero, experiências de classes pobres, excluídos, sociedades e grupos humanos escravizados para além das dimensões mais óbvias e cruéis desses processos, um novo olhar para a política e sentimentos, dentre outros temas sensíveis. Foi exatamente contra essa historiografia, ancorada nos estudos de uma história social vista de baixo, dos excluídos e no âmbito da história cultural, que assistimos às fortes reações conservadoras sustentadas em formatos como redes sociais, youtubers e blogs diversos.

Para ilustrar o que quero dizer, irei apresentar um exemplo de circulação de uma fonte, procurando contemplar certo circuito da informação histórica e midiática produzido a partir dela. Uma matriz geradora cujo percurso de construção, apropriação e divulgação foi estruturado para justificar alguns argumentos em favor do golpe em 1964.

Em 2009 a jornalista Mariza Tavares apresentou no site da CBN (rádio que compõe o conglomerado das organizações Globo) uma matéria feita com doses de sensacionalismo. Referia-se a um dossiê bombástico sobre uma articulação militarizada de Leonel Brizola para instaurar uma revolução comunista no Brasil em princípio da década de 1960, por meio dos chamados Grupos dos 11. Na prática, os grupos formados sob a liderança de Leonel Brizola tinham como objetivo pressionar para a aplicação das chamadas reformas de base do governo João Goulart, mas nunca tiveram grande repercussão nacional.

Em matéria intitulada: "Memória de 1964 - o dossiê do braço armado de Brizola”, a jornalista afirmava que teria chegado à CBN um documento, produzido pelos militares, que descortinava todas as ações e instruções do grupo para tomada de poder e implantação do comunismo no país por meio dessa organização. 
O que a jornalista omite, ou não sabia, é que as informações contidas no "estrondoso" dossiê já haviam sido divulgadas em vários lugares, como jornais brasileiros desde os anos 1960, a exemplo da Gazeta, no Rio Grande do Sul, e do Jornal do Brasil, no Rio de Janeiro, ou mesmo em livros como o de Adolfo Couto chamado Revolução de 1964: versão e fato, no qual o autor também afirma ter utilizado tais documentos "secretos" em suas pesquisas. Aqui se destaca a constante reafirmação dessas fontes como "secretas", "inéditas" e "bombásticas", como qualificadores de sua pretensa importância para a compreensão do período. Desse modo, o próprio tratamento dado ao registro é envolto nos mesmos protocolos jornalísticos de construção de um episódio que pretende se tornar emblemático para dada audiência.

Essa fonte já era também conhecida dos historiadores e outros pesquisadores, como a historiadora Marli Baldissera, da Universidade Federal do Rio Grande do Sul (UFRGS), que havia trabalhado com o documento. Ao ser entrevistada por Diogo Pacheco, em sua dissertação de mestrado sobre o tema intitulada Ecos da Resistência: os Grupos dos Onze e os trabalhismos em Santa Catarina (1961-1964), a professora afirmou que: "a cópia foi conseguida em condições curiosas: primeiro era uma cópia escrita à mão num caderno, que alguém que não se identificou passou ao entrevistador; assim que fora copiada, seu dono pegara o original e jogara-o no fogo, queimando-o" (Pacheco, 2012, p. 164). Circunstâncias parecidas foram narradas pela jornalista Mariza Tavares ao apresentar o material:

"Este é o documento a que me referi. O Exército não sabe que este dossiê ainda existe, porque foi dada uma ordem para que fosse destruído." Este era o texto do curto bilhete que acompanhava o pacote que recebi pelo correio, enviado por uma ouvinte fiel da CBN. Dentro, um calhamaço de 64 páginas já amareladas, no qual chamava atenção o carimbo no alto, em letras garrafais: SECRETO. A ditadura militar brasileira incinerou regularmente documentos sigilosos. Este dossiê estava em poder de um militar que preferiu desobedecer à ordem e decidiu guardar os papéis em casa. (Tavares apud Pacheco, 2012, p. 163)

Outras dissertações e artigos já mencionaram tal fonte, mas nenhum deles conseguiu atestar a veracidade de seu teor, especialmente porque os caminhos de sua produção são sempre nebulosos, envoltos em diversas controvérsias. Além disso, é bastante improvável considerar que militares tivessem o interesse 
de classificar tal registro como secreto, uma vez que traria um conteúdo que favorecia diretamente as justificativas para o Golpe em 1964. Na verdade, muitos indícios apontam para que a fonte tenha sido plantada para ajudar a justificar o golpe. O historiador Diogo Pacheco é o que esteve mais próximo de decifrar seus caminhos, ao localizar a documentação em um processo sobre um preso político. Pacheco afirma que ela realmente foi gerada na primeira metade dos anos de 1960:

Felizmente, durante a pesquisa, encontramos a documentação anexada ao processo referente ao carteiro Nezio Jacques Pereira [...] Fica evidente nas conclusões e durante todo o processo que tal documentação não foi encontrada junto aos inquiridos do processo do grupo dos Correios de Florianópolis. O anexo se deu, como está claro, posteriormente aos depoimentos e serviu para demonstrar o caráter radical e supostamente violento dos grupos de comandos nacionalistas. (Pacheco, 2012, p. 165)

Pacheco analisa diversos aspectos do registro que colocam em xeque as informações e a autoria de sua produção, especialmente pelo caráter formalista, violento e caricaturado em relação aos grupos de esquerda no texto. Aspectos muito parecidos com outra documentação plantada que, em 1937, havia servido para legitimar o golpe de Estado, sob argumento de estarmos na iminência de um golpe "judaico-comunista". Foi o chamado Plano Cohen, cujas principais teses foram idealizadas pelo então capitão do exército Olympio Mourão Filho, um dos principais protagonistas do Golpe de 1964.

Quarenta e cinco anos depois, quando Mariza Tavares coloca o registro novamente na cena pública, ele entra em novo circuito de difusão por novas mídias como blogs e redes sociais, suscitando novamente os mesmos argumentos de 1964.

A matéria, misteriosamente, foi retirada do ar e de todos os acessos do site da CBN. Para acessá-la recorri à sua reprodução em outros registros, como a já citada dissertação de Diogo Pacheco. Numa última tentativa, em 11 de março de 2019, o link continuava inacessível. ${ }^{7}$ Localizei ainda referências à matéria no Facebook, e existem outras referências localizadas em inúmeras páginas militares ou de apologia aos militares, a exemplo da Ternuma, página conservadora, "terrorismo nunca mais", que traz a matéria na íntegra ("Memória 1964...”, 2013), sendo a mais recente postada no dia 27 de setembro de 2018 
num blog do escritor Emir Laranjeira que apresenta até mesmo fragmentos do suposto dossiê. ${ }^{8}$

Ainda em 2009 a matéria de Mariza Tavares serviu como base de capítulo da obra de Leandro Narloch no já citado livro Guia politicamente incorreto da História do Brasil. No capítulo intitulado "Três coisas que a tortura não esconde" (Narloch, 2009, p. 266) o jornalista dedica um tópico para defender que "a guerrilha provocou o endurecimento do regime militar" (p. 268). Os argumentos do jornalista sobre os motivos ou justificativas para o golpe se assentam em três matrizes fundamentais: a) Cuba e o risco do modelo comunista a ser implantado no país; b) os militantes de esquerda preparavam um golpe iminente; c) os militares somente endureceram suas ações por causa das provocações desses militantes.

Para fundamentar seus argumentos, o autor utiliza exatamente as informações retiradas da matéria produzida por Mariza Tavares, sem problematizá-la. Diz Narloch: “A ideia era formar, em todo [o] país, milhares de pequenos grupos guerrilheiros que seriam mobilizados para uma eventual tomada de poder. Um dossiê encontrado no começo de 2009, pela Rádio CBN, trouxe à tona relatório de uma investigação militar sobre os Grupos dos Onze" (Narloch, 2009, p. 269).

Do mesmo modo que Mariza Tavares, Narloch também não investiga a fonte e, além de não checar a procedência, não questiona seu conteúdo, tampouco apresenta outros registros para fundamentar suas conclusões. Assim, afirma que: "Alguém poderá dizer que a reação dos militares ao terrorismo foi exagerada [...]. Isso pode ser verdade, mas não era seguro pensar assim naquela época. Qualquer notícia de movimentação comunista era um motivo justo de preocupação" (Narloch, 2009, p. 274).

Boa parte das informações contidas na obra de Narloch praticam aquilo que podemos chamar de história abusiva, isso porque ela efetiva um tipo de produção que utiliza registros e fontes originais, teses e dissertações, mutilando resultados e conclusões de maneira a referendar seus argumentos. Ao trabalhar com textos de historiadores consagrados pretende construir uma pretensa legitimidade de fala para suas conclusões, todavia, sua narrativa da história não se coaduna nem mesmo com a pluralidade do pensamento. Evoca o discurso de que é preciso apresentar outras versões da história, diferentes daquela que seria "militante", mas realiza exatamente o que diz combater, como se pode 
constatar quando afirma seguidamente que, caso os militares não tivessem assumido o poder em 1964, teríamos vivido uma tragédia de proporções épicas.

Menciono novamente o capítulo em que Narloch trata do período da ditadura militar no Brasil, quando apresenta suposições sobre o que poderia ter acontecido caso os comunistas tivessem assumido o poder no país. Inicialmente, argumenta que: "Em 21 anos as ações antiterrorismo criaram 380 vítimas [...] É muito menos que os 30 mil mortos pela ditadura Argentina ou a estimativa de 3 mil vítimas dos militares do Chile" (Narloch, 2009, p. 276, grifos meus).

O jornalista vai além, ao argumentar que: "Se o Brasil tivesse um regime como cubano ou chinês, como sonhavam os guerrilheiros de esquerda, pelo menos mais de 88 mil pessoas seriam mortas" (Narloch, 2009, p. 276, grifos meus).

Percebamos como o jornalista trata os crimes de torturas e assassinatos do Estado brasileiro como "ações antiterroristas" e que, portanto, as "380 vítimas" foram, na verdade, um efeito colateral menor, frente aos riscos de se instalar aqui o modelo que "os guerrilheiros sonhavam". O número também seria irrelevante, quando comparado a outros países da América Latina. Desse modo, continua a reafirmar uma teoria do mal menor, uma vez que os militantes de esquerda estavam prestes a implantar uma ditadura comunista no país. O segundo argumento é ainda mais problemático ao afirmar que, caso os militares não tivessem intervindo, quase 90 mil pessoas tinham morrido no país. Faz isso de forma anacrônica, posto que realiza uma equivalência entre realidades que são totalmente distintas e induz à conclusão de que, portanto, o golpe foi uma ação salvacionista do país, corroborando os mesmos argumentos elencados pelos militares e seus apoiadores em 1964.

Vejamos, num trecho do programa televisivo com título idêntico ao do livro de Narloch, uma fala do cantor Lobão:

Temos que recontar essa história de 64, essa história como se fosse um golpe... os militares foram forçados a intervir porque já tava (sic) uma baderna. O Jango decretou estado de sítio, estava meio Venezuela, como está agora, não tinha porra nenhuma, os caminhões chegando nas ruas para distribuir açúcar, víveres para a população, não tinha água, num tinha luz... (Lobão) ${ }^{10}$

Tais narrativas são poderosos instrumentos para a afirmação de uma versão reacionária do episódio, na medida em que repetem os mesmos 
argumentos dos militares sobre 1964 para justificá-lo. Em sua versão televisiva, a narrativa ensejada pela obra reforça uma articulação negativa com o ensino de história e com professores de história classificados como esquerdistas, que, em sua maioria, mentem. Vejamos alguns trechos, deflagrados pelo youtuber e apresentador do programa Felipe Castanhari, a alguns dos entrevistados: "Mas por que ficou para [a] história que os guerrilheiros lutaram pela democracia?

A ditadura acabou, a esquerda tinha as redações dos jornais, os centros culturais, e as universidades. E com o tempo foi aumentando e agora tem as escolas também e os professores do ensino médio que ensinam que o José Genuíno lutava pela liberdade. (Luiz Felipe Pondé - filósofo)

Eu peguei um colégio, cujas características não eram de esquerda, mas a esquerda já tinha entrando de forma subliminar. Você tinha que fazer música meio Chico Buarque... (Lobão - cantor)

Historicamente a falácia venceu a história, a versão venceu o fato... você pega qualquer livro didático hoje que tem no Brasil, no ensino médio por exemplo, tá lá escrito, que a luta armada levou à democracia. (Marco Antônio Villa - historiador)

Por fim, uma fala que talvez resuma muito bem a forma como os discursos se organizam para produzir a desqualificação de historiadores e professores de história:

A Esquerda brasileira, que se diz ter combatido pela liberdade, mente! Grande parte dos professores de história também mente! (Luiz Felipe Pondé) ${ }^{11}$

Os quatro trechos aqui apresentados efetivam alguns graves problemas de compreensão sobre os conteúdos históricos e são, por sua vez, claras manipulações da informação a fim de convencer que toda a produção historiográfica produzida sobre a ditadura militar nos últimos 30 anos é falsa. Os argumentos são generalistas, sem apresentação concreta de dados nem referências que sustentem tais afirmações, mesmo daquele que tem familiaridade com o campo, o historiador Marco Antônio Villa - pelo contrário, trata ele de desqualificar toda a historiografia nacional dizendo que "historicamente a falácia venceu a história, a versão venceu o fato", e ainda que "qualquer livro 
didático hoje que tem no Brasil, no ensino médio por exemplo, tá lá escrito, que a luta armada levou à democracia”. Numa reflexão mal-intencionada o historiador não apresenta sequer um dado que sustente afirmações tão graves e contundentes.

Nos últimos anos, o tema da ditadura militar brasileira assumiu o primeiro plano nos debates sobre a história recente no Brasil, impulsionado pelo acirramento político e pela polarização que se apresentou, especialmente depois de 2013. Nesse cenário, o acontecimento tem sido objeto de intensas disputas em discursos e representações na cena pública. As informações contidas na obra do jornalista e o tipo de narrativa histórica que ela enseja, de alguma maneira, se coaduna e alimenta os argumentos recentes de negação do episódio.

Não que outras obras não projetem argumentos parecidos, a exemplo da obra do próprio Villa em sua Ditadura à brasileira, de 2014, mas nos últimos anos essas versões ganharam cada vez mais espaço não somente entre o grande público, também entre autoridades políticas, acadêmicas e até jurídicas que abordam o tema. Menciono dois episódios recentes a seguir.

No dia 17 de outubro de 2018, alegando prescrição, a Justiça de São Paulo resolveu extinguir a ação civil que vinha sendo movida pela família do jornalista Luiz Eduardo Merlino contra o cel. Carlos Brilhante Ustra que, em 2012, havia sido condenado a pagamento de indenização em virtude da morte do jornalista nas dependências do DOI-Codi (“TJ derruba...”, 2018). Merlino tinha 23 anos em 1971, quando foi levado de sua residência para depor. Torturado por 24 horas ininterruptas, o jornalista faleceu, o que, posteriormente, foi mascarado como suicídio por agentes da ditadura, versão que constou de laudo necroscópico assinado por Isaac Abramovitch e Abelardo Orsini.

Em resposta ao recurso, os desembargadores Luiz Fernando Salles Rossi, Mauro Conti Machado e Milton Paulo Carvalho o indeferiram sob o argumento de que o Brasil teve "uma suposta ditadura" e o cel. Brilhante Ustra, chefe do quartel de operações da repressão durante o regime militar, teria sido "um suposto torturador". Na ocasião os desembargadores resolveram considerar irrelevantes os relatos de presos políticos que haviam prestado o seu depoimento à Comissão da Verdade e consideraram como válido o laudo necroscópico, apontado pela mesma comissão como fraudulento: “As testemunhas não acompanharam a ação de tortura presencialmente. E os depoimentos têm 
reservas pois eram presos políticos, estavam em condição idêntica à do jornalista", sustentou Rossi, que considerou o conteúdo do processo "sem prova da culpa e prática" para condenar Ustra (“Justiça de SP...”, 2018).

Representativas, também, foram as palavras do ministro do Supremo, Dias Toffoli, ao dizer que preferiria se referir a 1964 como o "movimento de 1964" e não como ditadura militar (“Toffoli diz...", 2018). Durante um seminário sobre os 30 anos da Constituição de 1988, o ministro afirmou:

Os militares foram um instrumento de intervenção e, se algum erro cometeu, foi, ao invés de ser o moderador que, em outros momentos da história, interveio e saiu, eles acabaram optando por ficar. E o desgaste da ilegitimidade em todo esse período que acabou recaindo sobre essa importante instituição nacional que são as Forças Armadas. Por isso que hoje eu não me refiro mais nem a golpe e nem a revolução de 1964. Eu me refiro a movimento de 1964. (“Último Segundo..., 2018)

Tais afirmações se constituem em graves relativizações e negações públicas do episódio, posto que todas as ações e reivindicações da memória se assentam no reconhecimento histórico e jurídico da ruptura democrática e na implantação de um estado de exceção constituído em 1964. Afirmações desse tipo, feitas por algumas das principais autoridades jurídicas do país, demonstram a gravidade do momento vivido.

Tanto nas falas apresentadas no programa de televisão como naquelas das autoridades jurídicas aqui mencionadas, é pertinente afirmar que no centro desses debates está uma disputa sobre a verdade ou sua negação, argumento que tem sido usado para desqualificar a incontestabilidade de tais eventos. Não são questionamentos apenas sobre as narrativas que os formulam, mas sobre as próprias ocorrências em sua condição de acontecência, como nos diria Paul Ricoeur. Assim, podemos também pensar em usos e abusos da própria ideia de verdade propagada nessas formulações, aspectos que se relacionam, por sua vez, às ideias de abuso da história na negação dos acontecimentos históricos em sua difusão pelas mais variadas mídias.

É fundamental darmos especial atenção ao novo espaço dessas disputas, ou seja, o universo virtual, sobretudo porque este tem se constituído em poderoso espaço de educação histórica, influenciando até mesmo na diminuição na leitura de livros didáticos de história, agora desqualificados como sendo "os livros do MEC". ${ }^{12}$ 
Essa produção tem sido lócus eficiente de um novo movimento de negação histórica, fenômeno muito mais complexo e difuso do que vimos em outras ondas negacionistas cuja produção esteve inscrita em sujeitos de discursos muito bem delimitados. Os historiadores negacionistas do Holocausto na França, na Alemanha e nos Estados Unidos ainda podem ser inscritos em certos protocolos científicos de produção que nos permitem refutá-los no mesmo campo de suas argumentações, a exemplo do famoso processo movido pelo historiador negacionista David Irving contra a também historiadora norte-americana Deborah Lipstardt.

David Irving, que sempre havia proposto uma leitura alternativa da atuação da Alemanha na guerra e, especialmente, sobre o papel de Hitler no episódio, passou a relativizar e mesmo negar o Holocausto, câmaras de gás e os campos de extermínio de Auschwitz. Irving, não se conformando em apenas apresentar suas teses, moveu o processo contra Lipstardt alegando que ela o havia difamado em sua obra, ao argumentar que ele havia distorcido os fatos ocorridos na Alemanha nazista. Irving, como sabemos, perdeu o processo e, como conclusão do caso, o juiz Charles Gray deliberou que ele "reproduziu evidências históricas erroneamente e as manipulou", qualificando-o ainda como antissemita e racista, "um polemista de direita pró-nazista" ("Holocausto...", 2000). Diz parte da sentença:

A meu ver, é incontestável que Irving pode ser descrito como negador do Holocausto [...] Não apenas ele nega a existência de câmaras de gás em Auschwitz e afirma que nenhum judeu foi morto em câmaras de gás no local, como já o fez em diversas ocasiões e, por vezes, em termos altamente ofensivos [...] As acusações, que constatei serem em grande medida verdadeiras, incluem a de que, por razões ideológicas próprias, Irving vem, de maneira persistente e proposital, reproduzindo erroneamente e manipulando evidências históricas. (“Holocausto...", 2000)

Tanto a defesa quanto a acusação lançaram mão de diversos documentos históricos e análises de registros para sustentarem suas posições. Ao longo dos dias, foram expostas metodologias e as análises pelas quais se desenvolveu a produção da narrativa de Irving que, finalmente, foi desqualificada, tanto por seus procedimentos como pela maneira como o historiador chegou às suas conclusões. Tais elementos só foram possíveis porque a arena sobre a reflexão 
dos usos dos registros e mesmo sobre as fontes estava delimitada. De alguma forma, toda a refutação foi admissível ao se demonstrar como, deliberadamente, o historiador utilizou os registros para favorecer uma visão muito particular dos acontecimentos que narrava. Assim, o princípio de reflexão da verdade de alguma maneira podia ser colocado em xeque/afirmado/negado a partir de referentes delimitados na constituição discursiva. Além disso, temos acesso aos livros e às fontes utilizadas como base da pesquisa.

Quando pensamos sobre a nova onda negacionista com a qual deparamos, percebemos as dificuldades de encontrarmos, por exemplo, os protocolos de constituição desses argumentos, uma vez que eles se legitimam muito mais pela forma de apresentação do que por seu conteúdo. O mais grave, sua aceitação social, tem dispensado dados e fontes sobre os quais tais afirmações são feitas.

Ao utilizarem, ao mesmo tempo, formatos, textos, imagens e fontes muito distintos, pulverizam os elementos estruturais de suas narrativas, de modo que em alguns momentos é impossível identificarmos suas fontes de constituição, ou de dar uma resposta rápida e eficaz aos seus argumentos, posto que sua difusão é tão acelerada quanto a forma pela qual ela é produzida.

Certo que, numa investigação mais acurada, podemos reconstituir seus fundadores de sentido, porém, é preciso destacar que os próprios protocolos de verdade e sua verificação são atingidos pela avassaladora velocidade sob a qual esses conteúdos são apresentados no cotidiano. Assim, antes mesmo de elaborarmos instrumentais para sua desconstrução, outros aspectos se sobrepõem a essa produção, tornando o trabalho de investigação desses conteúdos uma operação de caça quase de elementos etéreos.

\section{Problemas de “Verdade” NUMA ERA PÓS}

Compreender as apropriações do passado como fenômeno contemporâneo nessa rede de produção e produtores nos leva a considerar que esses elementos transformaram significativamente os usos do passado em sua dimensão política. Nesse caso, o ensino também foi atingido frontalmente pelos problemas próprios desse tempo, em que somos confrontados pela emergência de ideias de pós-verdade e pelas quebras dos referentes epistemológicos e sociais sob os quais boa parte de nossa produção científica esteve assentada, seja de informação ou conhecimento. Lembremos os recentes episódios de 
negacionismos a diversos pressupostos científicos, alguns até risíveis, a exemplo dos terraplanistas, e até os mais graves como o movimento antivacinação que trouxe o retorno de doenças já erradicadas.

Nesse sentido, é preciso destacar que o próprio conceito de "Verdade" ganhou nova centralidade nos debates atuais sobre conhecimento, informação e posicionamento político. Não por acaso, em 2016, quando o dicionário Oxford escolheu "pós-verdade" a expressão daquele ano, passou a representar um conjunto de práticas nas quais os "fatos objetivos são menos influentes na opinião pública do que as emoções e as crenças pessoais" (El País, 19 nov. 2016). Mais do que o simples falseamento de fatos, parecemos deparar com um fenômeno que, segundo Christian Dunker,

Envolve uma combinação calculada de observações corretas, interpretações plausíveis e fontes confiáveis numa mistura que é, no conjunto, absolutamente falsa e interesseira. Não se trata de pedir ao interlocutor que acredite em premissas extraordinárias ou contraintuitivas, mas de explorar preconceitos que o destinatário cultiva. (Dunker, 2017, p. 38)

Assistimos, portanto, à emergência de discursos reativos e conservadores que se sustentam na difusão tanto de falsos contrários - como disse antes como de falsos similares, com a intenção deliberada de estimular conclusões altamente tendenciosas sobre os processos históricos. Nesse sentido, coloca-se como problema uma ação consumidora que se elabora solicitando uma mudança conservadora ao se opor frontalmente aos processos de transformação política, social ou cultural dessa sociedade.

Uma história para ensinar Homer Simpson é uma história adversa à reflexão crítica, que ignora os dados e registros do passado apresentados num jogo de conformação que prioriza tão somente seus efeitos políticos. Uma história que não se preocupa com as implicações éticas de suas formulações.

É preciso assumirmos que vivemos aqui o desafio sobre o alcance de nossos discursos na sociedade. Se nossas teses e dissertações estão disponíveis nos sites das universidades ou em portais que distribuem o acesso a artigos acadêmicos e outras obras gratuitas, isso tem pouca repercussão comparado ao conteúdo produzido em outros sites e plataformas. De fato, ao longo das décadas, nós historiadores não fizemos grandes esforços para nos conectarmos a um público maior que a audiência de nossas salas de aula ou leitores especializados. Os constantes 
dilemas sobre as disparidades entre o ensino de história na educação básica e a academia nos demonstram que, mesmo quando o público é prioritário, nossa produção margeou a sala de aula.

O medo da simplificação, ou mesmo da perda de legitimidade entre os pares, parece ter funcionado quase como um fantasma a assombrar a "boa reputação" dos historiadores e professores de história. Assim, construiu-se de fato um hiato entre nossas produções e a tradução delas para um público maior.

Essa produção conservadora e reacionária de história nos tem mostrado também os desafios de pensarmos as formas de leitura e consumo, referenciados em Certeau, como aquilo que também produz a partir de um processo complexo de apropriação. Inegavelmente, temos uma significativa audiência conservadora que acessa os conteúdos dessas obras aqui mencionados, mas ela não é única, e os espaços de redes sociais, blogs, vlogs e outras plataformas podem funcionar também como lugares de luta e tensão de ideias.

É preciso problematizarmos essas experiências na própria historicidade de suas formulações, estratos do tempo dos quais, segundo Koselleck (2006; 2014), só conseguiremos nos apropriar lançando sobre eles questões a fim de tentar significá-los entre suas permanências e mudanças. Nesse sentido, existe um verdadeiro magma de história e memória em constante movimento, atuando de maneira intensa, tanto nos subterrâneos como na superfície de nossas sociedades, e, em momentos de grande agitação, discursos que pareciam superados emergem em redes de partilha desses conteúdos. Desse modo, a história pública, longe de ser o espaço de atuação de alguns, deve ser uma prática agregada ao próprio fazer dos professores de história frente aos novos desafios de construção de nosso campo no tempo presente.

\section{REFERENNCIAS}

CERTEAU, Michel. A invenção do Cotidiano. 1: Artes de Fazer. Petrópolis: Vozes, 1998.

DUNKER, Christian. Subjetividade em tempo de pós-verdade. In: DUNKER, Christian et al. Ética e Pós-Verdade. Porto Alegre: Dublinense, 2017.

GUIA politicamente incorreto de História do Brasil. (Série de Programas). Produção: History Channel, 2017-2018. 
HOLOCAUSTO: revisionista sofre derrota em tribunal. Folha de S. Paulo, 12 abr. 2000. Disponível em: https://www1.folha.uol.com.br/fsp/mundo/ft1204200010. htm. Acesso em: 21 out. 2018.

JUSTIÇA DE SP: Brasil teve 'suposta ditadura' e Ustra não era torturador. Ponte Jornalismo. 17 out. 2018. Disponível em: https://ponte.org/para-justica-de-sp-brasil-teve-suposta-ditadura-e-chefe-do-doi-codi-nao-era-torturador/. Acesso em: 19 out. 2018.

KOSELLECK, Reinhart. Estratos do tempo: estudos sobre história. Rio de Janeiro: Ed. PUC-Rio, 2014.

KOSELLECK, Reinhart. Futuro passado: contribuição à semântica dos tempos históricos. Rio de Janeiro: Ed. PUC-Rio, 2006.

MEMÓRIA 1964. O dossiê do braço armado de Brizola. 2018. Disponível em: https:// emirlarangeira.blogspot.com/2018/09/memoria-1964-o-dossie-do-braco-armado. html? m=1\&fbclid=IwAR0hfdl4aiGN---RIWsqpPrIIq6ypnz7gp2unyId5FmatiQktW1hXtjG5BQ . Acesso em: 1 nov. 2018.

MEMÓRIA 1964. O dossiê do braço armado de Brizola. 2013. Disponível em: www. ternuma.com.br/index.php/2013-08-22-03-34-31/373-memoria-1964-o-dossie-do-braco-armado-de-brizola. Acesso em: 21 out. 2018.

NARLOCH, Leandro. Guia politicamente incorreto da História do Brasil. São Paulo: Leya, 2009.

PACHECO, Diego. Ecos da resistência: os Grupos dos Onze e os trabalhismos em Santa Catarina (1961-1964). 2012. Dissertação (Mestrado em História) Universidade Federal de Santa Catarina (UFSC), Centro de Filosofia e Ciências Humanas. Florianópolis, 2012.

TJ DERRUBA decisão que mandou Ustra pagar indenização à família de jornalista morto na ditadura. O Globo. 17 out. 2018. Disponível em: https://g1.globo.com/ sp/sao-paulo/noticia/2018/10/17/tj-derruba-decisao-que-mandou-ustra -pagar-indenizacao-a-familia-de-jornalista-morto-na-di...

TOFFOLI DIZ que hoje prefere chamar golpe militar de 'movimento de 1964'. Folha de S. Paulo. 1 out. 2018. Disponível em: https://www1.folha.uol.com.br/poder/2018/10/toffoli-diz-que-hoje-prefere-chamar-ditadura-militar-de-movimento-de-1964.shtml 21/10/2018.

ÚLTIMO SEGUNDO - IG. 2018. Disponível em: https://ultimosegundo.ig.com.br/ politica/2018-10-01/dias-toffoli-movimento-de-1964.html.

\section{NOTAS}

1 “The Simpsons [...] é uma série de animação e sitcom norte-americana criada por Matt Groening para a Fox Broadcasting Company. A série é uma paródia satírica do estilo de 
vida da classe média dos Estados Unidos, simbolizada pela família protagonista, que consiste de Homer Jay Simpson, Marjorie (Marge) Bouvier Simpson, Bartholomew (Bart) Simpson, Elisabeth (Lisa) Marie Simpson e Margareth (Maggie) Simpson. A série se passa na fictícia cidade de Springfield e satiriza a cultura e a sociedade norte-americanas, a televisão e vários aspectos da condição humana. A família foi concebida por Groening pouco antes de uma solicitação do produtor James L. Brooks para uma série de curtas de animação. Groening elaborou uma família disfuncional e nomeou os personagens como os membros de sua própria família, substituindo o seu próprio nome por Bartholomew (Bart)" (WIKIPÉDIA, acesso em: 11 mar. 2019).

2 Disponível em: https://www.youtube.com/watch?v=9AOy_rEpVxM.

${ }^{3}$ Luiz Felipe Pondé - Filósofo, in: Guia..., Episódio: 1968, Ditadura à Brasileira, 2018.

${ }^{4}$ Fundado em 1995, o History Channel foi criado em 1995 nos Estados Unidos. Pertence à A\&E Network, é transmitido para vários países, desde a América Latina à Europa.

${ }^{5}$ Lira Neto, Facebook, 20 out. 2017.

${ }^{6}$ São elas: as minisséries Os dias eram assim (Globo, 2017), Entre irmãs (Globo, 2018, ambientada nos anos 1930) e Dois irmãos (Globo, 2017, ambientada entre as décadas de 1920 e 1980); as novelas Novo Mundo (Globo, 2017, século XIX, chegada da corte portuguesa), Tempo de Amar (Globo, 2017-2018, primeiras décadas do século XX), Orgulho e Paixão (Globo, 2018, ambientada na década de 1910), Deus salve o Rei (Globo, 2018, ambientada na Idade Média), Escrava Mãe (Record, 2017, ambientada no século XVIII, com temática da escravidão), A Terra Prometida (Record, 2017, século XII a.C.), O Rico e Lázaro (Record, 2017, século VI a.C.) e Belaventura (Record, 2018, ambientada no século XV).

${ }^{7}$ Link original da rádio CBN de 2009: http://cbn.globoradio.globo.com/hotsites/grupo-dosonze/GRUPO-DOS-ONZE.htm. Endereço eletrônico capturado na dissertação de Diogo Pacheco; minha busca no próprio site da CBN não teve sucesso.

${ }^{8}$ O blog do escritor Emir Laranjeira: https://emirlarangeira.blogspot.com/2018/09/memoria-1964-o-dossie-do-braco-armado.html.

9 Segundo os dados da Comissão Nacional da Verdade (CNV), no relatório apresentado em 2014, os números oficiais são de 434 mortos e desaparecidos, além de milhares de torturados.

${ }^{10}$ Lobão - Cantor, in: Guia..., Episódio: Ditadura Militar, 2017.

${ }^{11}$ Luiz Felipe Pondé - Filósofo, in: Guia..., Episódio: 1968, Ditadura à Brasileira, 2018.

${ }^{12}$ Entre os anos de 2007 e 2015 assistimos a uma queda de mais de 50\% nas menções de leituras do livro didático segundo dados da pesquisa Retratos da Leitura no Brasil; ver: http://prolivro.org.br/home/.

Artigo recebido em 15 de abril de 2019. Aprovado em 4 de julho de 2019. 